\title{
Kant'ın Grenze ve Schranke Ayrımı Yoluyla Felsefenin Yapısı Hakkında Bir Soruşturma
}

\section{An Inquiry in Philosophy Concerning Its Structure with Respect to Kant's Division of Grenze and Schranke}

\author{
Özgüç Güven ${ }^{1}$ (1)
}

Doç. Dr., İstanbul Üniversitesi, Edebiyat Fakültesi, Felsefe Bölümü, İstanbul, Türkiye

ORCID: Ö.G. 0000-0001-7223-0356

Sorumlu yazar/Corresponding author: Özgüç Güven,

İstanbul Üniversitesi, Edebiyat Fakültesi, Felsefe Bölümü, İstanbul, Türkiye

E-mail/E-posta: ozguc@istanbul.edu.tr

Başvuru/Submitted: 15.12.2019 Revizyon Talebi/Revision Requested: 24.12.2019

Son Revizyon/Last Revision Received: 25.12.2019

Kabul/Accepted: 27.12 .2019

\section{Atıf/Citation:}

Guven, Ozguc. (2019). “Kant'ın Grenze ve Schranke Ayrımı Yoluyla Felsefenin Yapısı Hakkında Bir Soruşturma" Felsefe ArkiviArchives of Philosophy, 51: 379-392. https://doi.org/10.26650/arcp2019-5133

\section{ÖZET}

Bu çalışmada Kant'ın Grenze ve Schranke anlayışı incelenerek bu kavramlar arasındaki ayrımın felsefi etkinliğin yapısını betimlemeye elverişli bir yaklaşım olduğu öne sürülmüştür. Bu bakımdan felsefenin felsefesi (üst-felsefe) tartışmaları açısından söz konusu ayrımın verimli yanıtlar verdiği düşünülmektedir. Böylelikle "felsefe nedir?" sorusuna felsefe tarihi içinde verilmiş pek çok yanıtın, örneğin "felsefe soru sormaktır", "felsefe yolda olmaktır", "felsefe ne türden şeylerin var olduğunu ortaya koymaktır", "felsefe düşünceleri açık kılma etkinliğidir", "felsefe dünya sorunları karşısında bir arayıştır" vb. Grenze ve Schranke ayrımı yoluyla tutulabileceği savlanmaktadır. Aynı biçimde üst-felsefe kapsamındaki "felsefe neden yapılır?", "felsefede sorular nasıl ortaya çıkar?", "felsefe nasıl yapılmalıdır?" gibi pek çok soru da sınırları ve kısıtlamaları anarak açıkığa kavuşturulabilir. Anlaşılacağı üzere anılan tüm sorular felsefi etkinliğin kapsamını belirlemeye ilişkindir. Kapsam ise ikili yapıdadır. Birinci kapsam bütün tartışmaların içine konulduğu kısıtlama alanıdır. İkinci kapsam ise sınırlar alanıdır. Burası filozofun kavramsal donanımını sağlayan ufuk alanıdır. Filozofun elindeki donanımla, belirlediği, düzenlediği ve ne türden şeylerle ilgilendiğini serimlediği alandır. Öyleyse filozofların birbirlerinden ayrımları kısıtlamaları değiştirmeleri ve yeni sınırlar çizmeleri üzerinden konulabilir. Bu bağlamda Kant'ın Grenze ile Schranke ayrımını bilinebilir ile düşünebilir alanı imlemesi açısından dikkat çekicidir. Kant, bilinebilir alanı bir adaya, düşünülebilir alanı ise adayı içine alan bir denize benzetir. Ada sınırlarıyla bilinebilir, deniz ise kısıtlamalarla düşünülebilir. Bu ayrım aynı zamanda felsefi kurgulamaların ve metafiziğin alanını gösterir. Bilebilmenin karşıında düşünebilmenin enginliğini anlatır. Ne var ki, Kant'ın kısıtlamalarıyla yalnızca düşünebildiğini öne sürdüğü alan, ardından gelenlerce bilinebilir bir alan olarak düzenlendi. Bunun gerisindeki neden ise Kant'ın kısıtlamaları yerine yeni kısıtlamalar konmasıdır. Öyleyse kısıtlama ile sınırlama felsefi etkinliğin yapısını anlamak açısından üzerinde durulması gereken kavramlardır.

Anahtar Kelimeler: Üst-felsefe, Kant, sınır, kısıtlama, Grenze, Schranke 


\section{ABSTRACT}

In this paper, via Kant's understanding of Grenze (boundary) and Schranke (limit) it is proposed that these concepts offer an appropriate distinction for describing the structure of philosophical thought. In this respect, it is claimed that the Grenze and Schranke distinction gives efficient answers to the philosophy of philosophy (metaphilosophy) debates. For instance, concerning "what is philosophy?" many answers have been given such as "philosophy means being on the road", "philosophy is to reveal what kind of things exist ", "philosophy is the activity of clarifying thoughts", "philosophy is a quest for the problems of the world" and so on. Thus, it is suggested that Grenze and Schranke distinction should hold all these answers. Likewise, many questions such as "what is philosophy for?", "how should philosophy be done?", "how do philosophical questions arise?" can be clarified by mentioning the boundaries and limits. As will be understood, all the questions mentioned above are about determining the scope of philosophical activity. The scope is dual. The first scope is the limitation area in which all discussions are put. The second scope is the boundaries area. This is the horizon that provides the philosopher's conceptual equipment. It is this field in which the philosopher exposes his or her own utilities, by which he or she determines and organizes, and what kind of things he or she is interested in. Thus, the distinctions of philosophical thoughts can be established through modifying limits and drawing new boundaries. In this context, Kant's distinction between Grenze and Schranke is remarkable in terms of determining the field of knowable and the field of thinkable. Kant allegorizes the knowable field to an island and the thinkable field to a sea that includes the island. The island can be known with its boundaries and the sea can be thought with limitations. This distinction also shows the field of philosophical fictions and metaphysics, and explains the vastness of thinking in the face of knowing. However, the field where Kant claims to be able to think only with his limitations has been arranged as a field that can be known by the followers such as Hegel. Behind this variation is the introduction of new limitations instead of Kant's. Thus, boundary and limit are concepts that need to be emphasized in order to understand the structure of the philosophy activity.

Keywords: Metaphilosophy, Kant, limit, boundary, Grenze, Schranke 


\section{Giriş}

Çalışmamızda Kant' in felsefesinde yer alan Grenze ve Schranke ayrımı ${ }^{1}$ yoluyla felsefi soruşturmanın yapısı hakkında bir üst-felsefe [metaphilosophy] tartışması yürütmek amacındayız. Güdücü sorumuz şu: "Nasıl oluyor da felsefi görüşler, tutumlar ya da tavırlar bunca çeşitlilik taşıyabilmektedir?”. Söz konusu soruyu şu alt sorularla birlikte düşünebiliriz: Felsefede nesneleştirme nasıl yapılır? Bakış açısı çeşitliliği nasıl ortaya çıkar? Bir felsefi tavrın haklılığı neye dayanır? Bir felsefi tavır varken bir diğeri nasıl ortaya çıkar?

Bu soruların yanıtını şu öne sürümler üzerinden tartışacağız: Filozoflar, felsefelerinde kendi kısıtlamaları (Alm. Schranke, İng. limit(ation) ) yoluyla sınırlar (Alm. Grenze, İng. bound(ary) ) çizer. Her yeni kısıtlama bağlamı, yeni sınırlar ortaya koyar. Felsefe, kısıtlamaların türetildiği ve onlar yoluyla sınırların düzenlendiği bir etkinliktir. Tam bu noktada Kant şöyle der: "hiç kuşkusuz felsefe yalnızca kendi sınırlarını [grenzen] bilmekten oluşur."2

Şu durumda felsefi etkinliğin yapısının anlaşılması, Schranke ve Grenze ayrımıyla ne denmek istendiğinin sıkı biçimde belirlenmesine bağlı görünmektedir. Almancada ve İngilizcede olağan kullanımda birbiri yerine kullanılabilen bu iki kavramı hangi bakımlardan ayırabileceğimizi Kant felsefesi üzerinden ele alacağız.

1 Sözcüklerin etimolojisine baktığımızda sınırın karşılığı olarak Almancada kullanılan Grenzénin Almancaya Slavcadan geçtiği ve belgelenmiş kullanımının 13. yüzyıla kadar geri gittiği bilinmektedir. 16. yüzyılda Martin Luther' in Incil çevirisiyle birlikte kullanımı yaygınlaşır. Jacob ve Wilhelm Grimm kardeşler bu yaygınlığın nedenini Luther'in Grenze için bir açıklama yazmış olmasına bağlar. Luther, Grenzéyi, landmarke yerine kullanmıştır. Landmarke, bir araziyi belirleyen kesitlere gönderim yapar. Feodal dönemde mülk edinmenin koşulları ile yerel düzenlemeler arasındaki gerilimler Grenzenin kullanım bağlamının ortaya çıkmasına yol açar. 19. yüzyıl dolaylarında ulus devletlerin belirişi ile sözcügün kullanımı politik bir bağlam kazanır. Bunun nedeni politik ve askeri erkin yalnızca arazinin ortasına konumlanmak yerine çok daha geniş bir bölgeye yayılması olarak düşünülür. Böylece sınır düşüncesi gündeme gelir. Sözcüğün daha soyut kullanımının belirlemesi örneğin bilginin sınırları ya da daha zamansal örneğin tarihsel bir dönemin sınırları olarak genişletilmesi ise 18. ve 19. yüzyılda gerçekleşir. Soyut kullanımıyla ilgili olarak Grimm kardeşlerGrenze için dünyanın yüzeyindeki alanları bölümlemeye yönelik sanal çizgi anlamında bir başka kullanımın daha olduğunu yazar. Bu kullanımda Grenze, görünür olanla düşünülür olan arasında bağ kurmayı içerir. 18. yüzyılla birlikte Grenze, sınırı geçme, yasayı çiğneme anlamında kullanılır. Sınırla ilişkili sınırsılık (Grenzenlosigkeit) ve sonsuzluk (Unendlichkeit) bağlamları bu dönemde ortaya çıar. Öte yandan Friedrich Kluge "Etymologischen Wörterbuch der deutschen Sprache" adlı eserinde Grenzeyi, "Granne" sözcügü ile ilişkilendirilir. ( Friedrich Kluge, Etymologisches Wörterbuch der Deutschen Sprache (Berlin: Walter de Gruyter, 1975) p. 269.) Granne ise bir insana ya da hayvana ilişik kıl demektir. Bu çerçevede sınır bir şeye gerçekten ait olmayan fakat ondan tümüyle de ayrı olmayan bir şeydir.

Schranke ise Grimm kardeşlerin sözlüğünde kavga-alanının kapatılması, bent çekilmesi anlamlarıyla yer alır.

Türkçede sınırın, Yunanca sinora'dan geldiği bildirilir. Sinora iki sözcügün bileşiminden oluşur: sin-ora. Ora, sözcüğü oros, orismos, orizo sözcüklerinden türevlenen, tanımlamak anlamına gelir. Sin de ortaklık, bir aradalık gibi bir ön ek olduğu için sinora "bizi tanımlayan alan" anlamındadır.

(Deutsches Wörterbuch von Jacob und Wilhelm Grimm, 16 Bde. in 32 Teilbänden, Leipzig 1854-1961, Quellenverzeichnis Leipzig 1971, Spalten 124-153, hier: Spalte 125 (Kleinschreibung im Original), http:// woerterbuchnetz.de/cgi-bin/WBNetz/wbgui_py?sigle=DWB\&mode=Vernetzung\&lemid=GG27579« )

2 Kant, Kritik Der Reinen Vernunft A 726 / 727-B 755. 


\section{Sınırlamanın ${ }^{3}$ Ortaya Çıkış Bağlamı}

Bir nesne ile dışı belirlendiğinde sınırlama ortaya çıkar. Fakat nesnenin ne olduğu, nasıl elde edilebileceği, nerede durduğu/tutulduğu ortaya koyulmadan onu var kılmak olası görünmüyor. Wittgenstein'dan esinle bir nesne düşünebilmek için dünyanın çoktan tasarlanmış olması gerekir çünkü birliğini, nasıl kuşatıldığını ve içinde bulunduğu bütünü göstermeden, kısaca dünyaya yerleştirmeden nesne sergilenemez. Ancak dünya kendiliğinden orada değildir. Oluşturulması için ayrım koymak, kapsamını belirlemek, uzanımını serimlemek gerekir. Bu bağlamda dünya ve içindeki nesneleri belirlemek için sınırlar ve kısıtlamalar ortaya konulmalıdır. Platon'un "eklem yerlerinden dünyayı ayıran kavramları”‘ araması işte bu sınır ve kıııt koyma çabasıdır. Düşünebilme ve bilmenin sınır koyma ile ilgisini saptayan Aristoteles de sınırın [Yun. peras] bir şeyi belirleyebilmenin olanağı olduğunu ortaya koyar. ${ }^{5}$

İşte filozof dünya tasarlayarak sınırlar ve kısıtlamalar koyan kişidir. Filozofun dünyasına göre sınırların yapısı değişir. Sınırlar keskin, silik, belirsiz, kurmaca, doğal, zamansal, soyut olabilir. Şu durumda belirginleştirmemiz gereken sınır ve kısıtlama ayrımıdır.

\section{Kant'ta Grenze-Schranke İlişkisi}

Kant, Saf Aklın Eleştirisin'nde (SAE) transendental felsefeye ilişkin alışkın olunması gereken en yüksek kavramın olanaklı ve olanaksız arasındaki ayrım olduğunu belirtir. ${ }^{6}$ Ardından şöyle sürdürür: "Her ayrım bölünebilir bir kavram gerektirdiğinden çok daha yüksek bir kavramın verilmesi zorunludur. Bu ise genel olarak bir nesnenin kavramıdır.” Demek ki, Kant için nesnenin nasıl olanaklı olduğu transendental felsefenin anlaşılması için kaçınılmazdır. Yukarıda giriş bölümünde öne sürdüğümüze uygun olarak nesnenin olanağının sınır ve kısıtlama ayrımıyla ilgisini açık kılarak devam edelim.

Rudolf Eisler ${ }^{7}$ ve Hermann Cohen gibi Kant'la yakından ilgilenen pek çok akademisyen sınır ve kısıtlama ayrımının anlaşılmasının Kantçı felsefeyi kavramak açısından son derece önemli olduğunu bildirir. Hatta Cohen, Kantçı felsefeyi sınır-kavramların felsefesi olarak niteler. ${ }^{8}$ Bununla birlikte söz konusu ayrımın Kant'la başladığını öne sürmek yanlış olacaktır. Kant öncesi felsefe

3 Sınırlamayı, sınır ve kısıtlama bağlamını kapsayan çatı bir kavram olarak kullanıyoruz.

4 Plato, "Phaedrus", içinde Complete works, ed. D S Hutchinson John M.Cooper (Indianapolis, Ind.: Hackett Pub., 1997), xxx, $1808454 \mathrm{e}$.

5 Aristoteles için sınır şu anlamlara gelir:

1) Her bir şeyin en uzak noktası ve dışında bir şeyin hiçbir parçasını bulmanın olanaklı olmadığı ilk nokta ve kendisinden beride onun her parçasının bulunduğu ilk nokta 2) büyüklüğün her türlü formu veya büyüklüğü olan bir şeyin formu 3) her şeyin ereği (hareket ve eylemin başlangıç noktası değil, varış noktası. Ancak kimi zaman hem varış noktası, hem de hareket noktası eş deyişle ereksel neden) 4) her şeyin formel tözü ve özü. Çünkü formel töz ve öz, bilginin sınırıdır ve bilginin sınırı olarak, nesnenin de sınırıdır. O halde açık olarak "sınır" $ı$ ilke kadar, hatta ondan daha fazla sayıda anlamları olduğu ortaya çıkmaktadır: Çünkü ilke bir sınırdır; ama sınır, her zaman bir ilke değildir. (Aristotle, "Metaphysics", içinde The Complete Works of Aristotle: the Revised Oxford Translation, ed. Jonathan Barnes, c. II (Princeton: Princeton University Press, 2014), V, 17, 1022a4-5).

6 Immanuel Kant, Kritik Der Reinen Vernunft (Hamburg: Felix Meiner, 1956) A290-B346.

7 Rudolf Eisler, Kant Lexicon (Hildescheim: Olms, 1961), 225.

8 Hermann Cohen, Kants Theorie der Erfahrung (Berlin: Ferd. Dümmler's, 1871) p. 96. 
geleneğinde ayrım zaten vardır. ${ }^{9}$ Serena Feloj, Kant'ın Grenze ile Schranke arasında yaptığı ayrımın, Galileo, Kopernikus ve Wollf̧̧u felsefe çizgisinde bulunduğunu öne sürer. ${ }^{10}$ Feloj’a göre, Kant Hermann Samuel Reimarus'un Vernuftlehre eserinde yaptığı ayrımı sürdürmüştür. Fulda’da da, Kant'tan önce Leibniz' in dinamikle ilgili çalışmalarında Grenze ile Schranke sözcüklerini Latince terminus ve limes'la ilişkilendirdiğini bildirir. ${ }^{11}$ Terminus, bir arazinin sonu ya da belirlenimidir. Limes ise olumsuz, belirsiz biçimde düzenlenmişlik durumuna ve tamamlanamazlığa karşılık gelir. Leibniz' in sonsuz küçüklükler ve monadlar hakkındaki soruşturmaları onu sınırlamanın türleri hakkında araştırmaya yönlendirmiş görünmektedir. Kant Grenze ile Schranke ayrımının terminus ile limes ayrımına karşılık geldiğini gösterek: "limes (Schranke), terminus'tan (Grenze) farklıdır”12 demektedir.

Söz konusu bağlamda öğrencilerinden gelen ders notlarında Kant'ın limes (Schranke) ile terminus (Grenze) ayrımını olgunluk döneminde de koruduğu görünmektedir. Eleştirileri tamamladığı 1780-1790 yıllarından sonra 1790-1791 yılları arasında tarihlendirilen ontoloji ders notlarında Kant şöyle demektedir: ${ }^{13}$

Anlama yetisinin saf bir kavramı olan kısıtlama kavramı, matematiksel bir kavram olan sınır kavramı ile bağlantılıdır, tıpkı sonsuzluk kavramı gibi. Kendinde bir şeyin ölçüsü tümlüktür [totality] ve bu, şeylerin olağan ölçüsü olan mutlak büyüklüktür çünkü bütün [all] şeyler bu tümlüğün sınırlandırılmasıyla olanaklıdır. Sınır kavramı yalnızca fenomenlere <phenomenis> ilişkindir fakat kısıtlama ise noumenonlarla <noumenis>. Katı uzay sınır olarak yüzeyi, düzlemsel uzay sınır olarak çizgiyi, çizgi ise noktayı barındırır. (...) Kısıtlama <limes> ise değillemedir böylelikle bir şey en büyük şey olamaz <ut ens non sit maximum>.

Benzer biçimde 1794-1795 yılları arasında tarihlendirilen ontoloji ders notlarında Kant şöyle demektedir: ${ }^{14}$

Bir büyüklüğün neden bitimli olmadığının temeline değilleme denir. Kendisi uyarınca kuantumun en büyük <maksimum> olmadığ şeye, kısıtlama ya da kuşatma [boundedness] ${ }^{15}$ denir.

9 Bu nedenle Grenze-Schranke tartışmasına Kant’ın eleştiri öncesi dönemindeki çalışmalarında da rastlanır. Bu konuda bkz. Ebru Pehlivan, “Kant’ın Eleştiri Öncesi Eserlerinde Sınır Kavramı”, Felsefe Arkivi II, sayı 47 (2017): 46-54.

10 Serena Feloj, "Metaphor and Boundary: H. S. Reimarus' Vernunftlehre As Kant's Source”, Lebenswelt 1, sayı 1 (2011) 36.

11 F. Fulda, "Grenze, Schranke", içinde Historisches Wörterbuch der Philosophie, ed. Joachim Ritter ve Karlfried Gründer (Basel: Schwabe, 1974) 875.

12 Immanuel Kant, Lectures on Metaphysics, çev. Karl Ameriks ve Steve Naragon (Cambridge: Cambridge University Press, 1997) 28:644.

13 Immanuel Kant, Lectures on Metaphysics, çev. Karl Ameriks ve Steve Naragon (Cambridge: Cambridge University Press, 1997) 28:570 334.

14 Immanuel Kant, Lectures on Metaphysics, çev. Karl Ameriks ve Steve Naragon (Cambridge: Cambridge University Press, 1997) 29:994 463.

15 Boundary ile boundedness ayrımını tutmak için, kuşatmayı kullanmayı seçtik. 
Yalnızca aklın nesnesine kısıtlanmış [limited] denir, görünün nesnesine ise sınırlandırılmış [bounded] denir. Benzer biçimde kısıtsız ve sınırsız, salt aklın ya da duyuların bir nesnesi olup olmadığına göre denir.

Öyleyse sınırlar, kısıtlamalardan ayrıdır. Anlama yetisinin bir varlığının (noumenon) yalnızca kısıtlamaları (<limites; G: Schranken>) bulunur e.d. değilleme yalnızca anlama yetisine göre düşünülür. Demek ki, kısıtlama buradadır: bu nedenle bir noumenal kuantum <quantum noumenon> anlama yetisi aracılığıyla düşünülen bir büyüklüktür ve en büyük <maksimum> olmamak bakımından kısıtlanmıştır ve değilleme kısıtlama <limes; G: Schranken>) olarak adlandırılır çünkü kendi bağlamında kısıtlanmıştır. Sözgelimi insanın anlama yetisinin kısıtlamaları ya da sinırları, istenç.

Öte yandan, fenomenal bir kuantum <quantum phaenomenon>, büyüklüğünün belirlenimi ya da değillenmesi aynı zamanda görüye <intuitus> aitse sınırlanmıştır ya da bu şu demektir, kısıtlamanın temeli uzayda olumlu bir şey içerirse.

Görünün kısıtlanmast yoluyla belirlenen olumluya sınır denir.

Öyleyse, bu noktaya kadar Kant şunları söyler, sınır görünüşlerle ilgili, kısıtlama ise kendinde şeylere ilgilidir. Bunun yanı sıra bir büyüklügün sürekliliği de kısıtlamayla ilişkilidir. Belli bir büyüklüğü bir sona ulaşmadan bölebilme kısıtlamanın konusudur. Şu durumda Grenze ile Schranke ayrımı yoluyla Kant, kendi felsefesinin kurucu kavramları olan aşkınlık, transendentallik, olanaklı deneyim, görünüşler ve kendinde şeyler arasında ayrımları tutar. ${ }^{16}$ Şimdi bu ayrımları ayrıntılı biçimde ele alalım.

\section{Kant'ın Adası}

Kant Grenze ile Schranke ayrımını ortaya koymak için Saf Aklın Eleştirisinnin farklı bölümlerinde ada metaforunu kullanır: ${ }^{17}$

[Şimdiye dek] saf anlama yetisinin ülkesi boyunca gezinmek ve her bir parçasını soruşturmakla kalmadık, fakat aynı zamanda onu araştırdık ve içindeki her şey için bir yer belirledik. Ne var ki, bu ülke bir adadır, doğanın kendisince değişmez sınırlarla kapatılmıştır. Orası doğruluğun alanıdır (çekici bir ad), engin ve fırtınalı bir okyanusla çevrelenmiştir. Öyle ki, orada sis bulutları ve hızla eriyip yiten buzdağları, uydurma öykülerle yeni yerlerde keşif yolculuğuna çıkmış hayalperest denizciyi boş umutlara düşürmekte ve onu hiçbir zaman bırakamayacağı ama hiçbir zaman da sonuna dek götüremeyeceği serüvenlere sürüklemektedir.

16 Bu ayrımı başka bir dilegetirilişi ise şöyledir: "Schranke, fenomenal sınırı belirleyerek bilginin meşru alanını tayin ederken, aklın neyi bilemeyeceğine de işaret etmektedir. Grenze ise dışarıda neyin kaldığına göndermede bulunmak amacıyla kullanıldığından Kant, metafizik söz konusu olduğunda Grenze sözcüğünü tercih etmiştir." Ebru Pehlivan, "Kant'ta Öznenin Bilme, Eyleme ve İnanma Bakımından Sınırları", içinde Uluslararası Istanbul Felsefe Kongresi Bildiri Kitabı, ed. Mehmet Günenç (İstanbul: Mantık Derneği Yayınları, 2018), 102.

17 Kant, Kritik Der Reinen Vernunft A236-B294/295. 
Şu durumda ada metaforuyla sınırların bilginin ve doğruluğun alanını belirlediğini söyler. Bir de adanın dışı vardır, burası ise bilinmezler, yanılsamalar ve çatışkılar alanıdır. Anlama yetisi olağan kullanımı dışında buralarda da gezinmek istediğinde kısıtlamalarla karşılaşır ve işlevsiz kalır. ${ }^{18}$ Şu durumda o adanın yetisidir. Fakat, gerçekte sınırlanmış olsa da ada yayılımı belli olmayan bir alandır. Kant şöyle demektedir: ${ }^{19}$

Dünyanın yüzeyini (duyusal görünüşle uyumlu biçimde) bir tabak olarak tasarlarsam, ne kadar yayıldığını bilemem. Fakat deneyim bana şunu öğretir: nereye gidersem gideyim beni çevreleyen ve daha da ilerleyebileceğim bir uzay görürüm bundan dolayı, herhangi bir zamanda edimsel bilginin kısıtlamalarını bilirim fakat dünyanın tüm olanaklı betimlenişinin sınırlarını bilemem.

Biz sınırlarla neyin adada olduğunu biliriz ama bilinenler tüketilebilir değildir. Bu adadan öteye bakıldığında göz eriminin ötesinde belirsizlikler içinde kendini sunan kısıtlamalar fark edilir. Burası adanın dışıdır. Ayrı ayrı sunulsa da dış ve iç birliktedir. Bu ise transendental felsefedir.

Şimdi sırasıyla sınır ve kısıtlamanın Kant’taki kullanımına yakından bakalım.

\section{Grenze}

Kant'ın eleştirel felsefesi belirleyici yargı ile düşünümsel yargı ayrımı üzerinden düşünüldüğünde sınırın genellikle belirleyicilikle ilgili olduğu görülür. Kant bu belirleyicilik bağlamını imlemek için sınırı şu kapsamda kullanır:

1. Saf aklın bütün kapsamını hem sınırları hem de içeriğiyle eksiksiz ve genel ilkelere göre belirleyebilmek için. ${ }^{20}$ Bir başka deyişle saf aklın kaynakları ve sınırlarının belirlenmesi için ${ }^{21}$

18 Keskin de, sınırlama yoluyla Kant'ın bilme ve düşünme alanlarının belirlendiğini öne sürmektedir. Bkz. Gamze Keskin, "Kant'ın Ontolojik Kanıt Eleştirisinin Epistemolojik Temelleri" FLSF (Felsefe ve Sosyal Bilimler Dergisi), Say1 27, (2019), 105.

19 Kant, Kritik Der Reinen Vernunft A759-B787.

20 Immanuel Kant, Gelecekte Bilim Olarak Ortaya Çıkabilecek Her Metafiziğe Prolegomena, çev. İonna Kuçuradi ve Yusuf Örnek (Ankara: Türkiye Felsefe Kurumu, 2002) 9.

21 Kant, Kritik Der Reinen Vernunft A11-B25. 
2. Bilginin olanağının ortaya konulması, bilinebilir alanı saptamak ve deneyimin alanına işaret etmek ve yetilerin sunduğu kavrayışın ötesinin boş uzay olduğunu bildirmek için. ${ }^{22}$ Bunun yanı sıra neyin bilinemeyeceğini göstermek için. ${ }^{23}$

3. Anlama yetisinin kullanım kapsamını ${ }^{24}$ bunun yanı sıra bilme yetilerinin işbirliğini ve ayrı çalışma alanlarını vurgulamak için. Özellikle de anlama yetisi ve akıl ayrımının belirginleşmesinde sınırların çizilmesi gereklidir çünkü anlama yetisi kendiliğinden kendi a priori koşullarında çalışan bir yetidir buna karşılık akıl ise koşullu olanı koşulsuza taşımak ister. Akıl burada deneyimin sınırlarının aşılması ya da korunması sorunuyla karşılaşır. ${ }^{25}$ Çünkü anlama yetisi sınırları aştı̆̆ının farkına varmaz. ${ }^{26}$

\section{Mantığın alanının belirlenebilmesi için. ${ }^{27}$}

22 "Eğer bir bilginin bilim olarak serimlenmesi isteniyorsa, her şeyden önce onu diğer bilgilerden ayıranın, yani ona özgü olanın kesinlikle belirlenebilmesi gerekir; aksi halde bütün bilimler birbirine karışır ve hiçbiri kendi yapısına göre, esaslı bir biçimde ele alınamaz.” Kant, Gelecekte Bilim Olarak Ortaya Çıkabilecek Her Metafiziğe Prolegomena, 13.

"Öyleyse tüm insan bilgisi görülerle başlar, oradan kavramlara gider ve de idelerle sonlanır. Gerçi her üç öğe açısından, ilk bakışta tüm deneyimin sınırlarını [Grenzen] küçümsüyor görünen a priori bilgi kaynakları taşıyor olsa da tamamlanmış bir eleştiri bizi tüm aklın kurgusal kullanımında bu öğelerin hiçbir zaman olanaklı deneyim alanının ötesine geçemeyeceğine ve bu en yüksek bilgi-yetisinin gerçek görevinin tüm yöntemleri ve bunların ilkelerini yalnızca tüm olanaklı birlik ilkeleri -aralarında ereklerin birliği en önemlisi olmak üzere- ile uyum içinde doğanın en içlerine dek ulaşabilmek için kullanmak olduğuna, ama hiçbir zaman onun sınırının [Grenze] ötesine yükselmemesi gerektiği çünkü onun dışında bizim için boş uzaydan başka birşeyin bulunmadığına inandırır” Kant, Kritik Der Reinen Vernunft A VIII, A 702-B730.

23 "Olanaklı deneyimin sınırlarının ötesinde bulunanı bilmek şöyle dursun, hakkında tahminde bulunmaya bile kendilerine izin verilmemiştir; sadece yaşamda anlama yetisinin ve istemenin yönetilmesi için olanaklı, hatta onsuz olunamaz olan bir şeyi (kurgusal kullanılış için değil —çünkü ondan vazgeçmelidirler-, yalnızca pratik kullanılış için) var sayabilirler." Kant Gelecekte Bilim Olarak Ortaya Çıkabilecek Her Metafiziğe Prolegomena 27.

24 Kant, Kritik Der Reinen Vernunft A XVI.

25 "Anlama yetisinin kendiliğinden -kendisine yabancı yasalarca zorlanmadan, tamamıyla kendi isteğiyle- yalnızca düşünce varlıklarının oluşturduğu alana dalması tehlikesi yoktur. Ama anlama yetisi kurallarının deneyimdeki hep koşullu olan kullanılışından tam tatmin olamayan akıl, bu koşullar zincirinin tamamlanmasını isterse, o zaman anlama yetisi kendi alanının dıșına sürüklenerek, bir yandan bunca uzaklara giden bu dizide hiçbir deneyimin kavrayamayacağı deneyim nesneleri tasarımlar, bir yandan da (bu diziyi tamamlamak için) deneyimin büsbütün dışında noumenonlar arar; öyle ki bu zinciri onlara bağlayabilsin, böylece de en sonunda artık deneyimin koşullarından bağımsız olarak tutunduğu şeyi yine de tamlaştırabilsin. İşte bunlar transendental idelerdir. Bu ideler aklımızın doğal belirleniminin hakikî ama gizli amaçlarına göre, aşırı kavramlara değil de sırf deneyimin kullanılışını sonsuza dek geliştirmeye eğilimli olsalar bile, yine de önlenemeyen bir kuruntuyla anlama yetisine aşkın kullanılışın yolunu açabilirler. Bu kullanılışın, yanıltıcı olduğu halde, deneyimin sınırları [Grenzen der Erfahrung] içinde kalması — bunda ne kadar kararlı olunursa olsun — sağlanamaz; ancak bilimin öğrettikleriyle ve büyük çaba harcayarak sınırlar içinde tutulabilir." Kant, Gelecekte Bilim Olarak Ortaya Çıkabilecek Her Metafiziğe Prolegomena 85-86.

26 "Anlama yetisi deneyimin evine çok daha geniş bir bölme ekler, bunu sırf düşünce varlıklarıyla doldurur ve başkaca doğru olan kavramlarıyla kullanılışının sınırlarını aştığının, bir defacık bile olsun, farkına varmaz.” Kant, Gelecekte Bilim Olarak Ortaya Çıkabilecek Her Metafiziğe Prolegomena 67-68.

27 Kant, Kritik Der Reinen Vernunft B VIII. 
5. Metafiziğin boyutlarını ortaya koymak için. ${ }^{28}$ Bu bağlamda sınırların belirlenmesi dogmatik olmayan yeni metafizik anlayışın olanağıdır. ${ }^{29}$ Böylece kurgusal aklın kullanımı sırasında asla deneyimin sınırlarının ötesine geçmeye girişilmemesi için. ${ }^{30}$

6. Yargıların alanı tüm olanaklı deneyimi aşarak sınırların ötesine taşındığında, ${ }^{31}$ yanılsamanın ortaya çıktığını imlemek için. ${ }^{32}$ Kant'a göre kendinden önceki metafizikçiler sınırlar hakkında düşünmedikleri için altından kalkamayacakları düşünüşlerin peşine düşmüşlerdir. ${ }^{33}$

7. Kant Grenze kavramını bilginin (Erkenntnis) alanını ve bu alanın dışında kalan ideleri işaret etmek için kullanır. Bu bağlamda noumenon, negatif kullanımıyla bir sınır-kavram (Grenzbegriff) olarak Kant felsefesinde yer alır. ${ }^{34}$

Dolayısıyla Kant'ta sınırlar, belirleyici, saptanabilen, aşılma tehlikesi bulunan ancak içinde kalınması gereken bağlama işaret eder.

\section{Schranke}

Kant'in Schrankẻyi kullanım biçimleri göz önünde tutulduğunda anlama yetisindeki ile akıldaki kullanımına ilişkin ayrım yapmak gerekli görünmektedir. Bu kullanım bağlamı farklılığına karşın her iki kısıtlamada ortak olan tüketilemezlik vurgusudur.

Anlama yetisinin saf kavramları açısından düşünüldüğünde kısıtlama bir kategoriye karşılık gelir. Nitelik üst başlı̆̆ının altında sıralanan gerçeklik, değilleme kategorilerinin ardından kısıtlama kategorisi yer alır. Kant şöyle der: "Kısıtlama [Einschraenkung], değilleme ile gerçeklĭgin birleşiminden başka bir şey değildir." ${ }^{35}$ Kısıtlama, anlama yetisinin yargılardaki mantıksal işlevlerinde de sonsuz [Unendliche] işlevine karşılık gelir.

Yukarıda Kant'ın ders notlarında konu ettiğimiz kendisi aracılığıyla belli bir kuantumun son büyüklük olmadığını belirleyen kısıtlama düşüncesidir. Bu durumu Kant, SafAklın Eleştirisi B182/ B183-A143'te şöyle açar: Duyum zamanda bir varolana karşılık gelir. Değilleme ise zamanda bir varolmayana karşılık gelir. Gerçeklik ile değillemenin karşıtlı̆̆ı aynı zamanın dolu ya da boş ayırt

28 Kant, Kritik Der Reinen Vernunft B XXII.

29 Kant şöyle demektedir: "Metafiziği yeniden doğrultacak saf aklın eleştirisidir. Metafiziğin olanağını ya da olanaksızlı̆ı̆ı saptayacak ve kaynaklarını açığa çıkaracak, sınırlarıı gösterecek akıl yetisinin eleștirisidir." Kant, Kritik Der Reinen Vernunft A XVI.

30 Kant, Kritik Der Reinen Vernunft B XXIV.

31 Kant, Kritik Der Reinen Vernunft A3-B6.

32 "Görünüş deneyimde kullanıldığı sürece doğruluğu meydana getirir, ama deneyimin sınırnı geçip aşkın olduğu anda kuruntudan başka bir şey ortaya çıkarmaz." Kant, Gelecekte Bilim Olarak Ortaya Çıkabilecek Her Metafiziğe Prolegomena, 42.

33 Dogmatik metafizikçiler "saf aklın meşru ve doğal ama sırf deneyimde kullanılacak kavramları ve ilkeleriyle, böyle bir saf anlama yetisinin yapısını ve olanağını ya hiç düşünmemiş ya da düşünememiş oldukları için— belirli sınırlarını bilmedikleri ve bilemeyecekleri kavrayışlar peşine düşmüş olanların bile aklına gelmedi." Kant, Gelecekte Bilim Olarak Ortaya Çıkabilecek Her Metafiziğe Prolegomena 65.

34 Immanuel Kant, "Kritik der reinen Vernunft", içinde Kant's gesammelte Schriften Preußische Akademie der Wissenschaften, c. 3 (Berlin: Georg Reimer, 1911) A 253-B308, A288-289-B345.

35 Kant, Kritik Der Reinen Vernunft B111. 
edilmesini sağlar. Her bir duyumun bir derecesi ya da büyüklügü bulunur. Bu derece yoluyla aynı zaman daha çok ya da daha az olarak doldurulabilir. Aynı nesnenin tasarımına ilişkin olarak sıfırlanana kadar duyunun dereceleri bulunur. Dolayısıyla gerçeklik ile değilleme arasında bir bağıntı ve bağ hatta geçiş bulunur ki her gerçeklik bir quantum olarak tasarlansın. İşte bir kategori olarak düşünüldüğünde kısıtlama herhangi bir büyüklüğün dereceli olarak ele alınabilmesini sağlar. Buna koşut olarak SAE A166-B207'de Algının Beklentileri [Antizipationen der Wahrnemhmung] bölümünde Kant şöyle der: "tüm görünüşlerde, gerçek olan [Reale] duyumun nesnesi yoğunluklu bir büyüklük taşır e.d., derece taşır. Niteliklerin yoğunluğu sıfırlanana kadar azalabilir." ${ }^{\prime 6}$ Demek ki, kısıtlama belirli bir niceliğin durmaksızın bölünebilme olanağını karşılar. Ondalık basamakları düzenli yinelenmeden süren bir büyüklüğü düşünebilme, bir başka deyişle bir orantı yoluyla düşünülemeyen bir büyüklüğü düşünmek bir kısıtlama yoluyla olanaklıdır. Şu durumda sonlu ötesi bir büyüklük olan $\mathrm{N}_{1}$ alanı kısıtlama yoluyla elde edilir. ${ }^{37}$

Akıl söz konusu olduğunda, Kant'ın yukarıda andığımız ada benzetmesinde olduğu gibi ötede olan, aşan, kendisi yoluyla sınırların konulduğu bir kuşatma söz konusudur. Bu bağlamda matematik ve doğa bilimleri açısından bilim yapmanın aklın yapısından kaynaklanan kısıtlamaları olduğu ancak bu bilimlerde elde edilen bilginin sınırsız olduğu görülür. ${ }^{38}$ Ada, belirlenebilir olmak bakımından sınırlar içerir fakat bu sınırlar kapsamında nesneleri ve onların bilgisi engindir. Öte yandan adayı çevreleyen deniz bu adanın kısıtlamasıdır. Bundan dolayı Kant “öyleyse tüm olanaklı dünya betimlemelerinin sınırını [Grenze] değil, her defasında gerçek dünyanın kısıtlamalarını [Schranken] bilirim"39 demektedir. Bununla birlikte akıl, kendisinde bulunan ideler yoluyla,

36 Kant, Kritik Der Reinen Vernunft A3-B6.

37 "Sınırlar [grenzen] (yer kaplayan varlıklar söz konusu olduğunda) belirli bir yerin dışında bulunan ve onu çevreleyen uzayı varsayar. Kısıtlamalar [Schranken] ise böyle bir şeyi gerektirmezler; onlar yalnızca, mutlak tam olmadığı sürece büyüklüğü etkileyen değillemelerdir.” Kant, Gelecekte Bilim Olarak Ortaya Çıkabilecek Her Metafiziğe Prolegomena 106.

38 Matematik ve doğa biliminde insan aklı kısıtlamalar [Schranken]tanır ancak sınır [Grenze] tanımaz; yani kendi dışında, hiç ulaşamayacağı bir şeyin olduğunu kabul eder, ama kendisinin, kendi iç gelişiminde tamamlanacağını değil. Matematikte kavrayışların genişlemesi ve hep yeni buluşlar yapma olanağı sonsuzdur; aynı şekilde, sürdürülen deneyim ve bu deneyimin akılla birleştirilmesiyle yeni doğa özelliklerinin, yeni güçlerin ve yasaların bulunması olanağı da sonsuza gider. Ne var ki, buradaki kısıtlamalar [schranke] yanlış değerlendirilmemelidir, çünkü Matematik yalnızca görünüşlere götürür ve duyusal görünün nesnesi olmayan şey —Metafiziğin ve Ahlakın kavramları gibi_, onun alanının dışında kalır; Matematik ona götürmez, ona gerek duymaz da. Dolayısıyla bu bilimlere sürekli bir ilerleme ve yaklaşma, bir çeşit dokunma noktası ya da çizgisi yoktur. Doğa Bilimi şeylerin içini, yani kendisi görünüş olmayan ama yine de görünüşlerin en üst açıklama nedeni işini görebilecek şeyi bulmamızı hiçbir zaman sağlayamaz; ayrıca bunu kendi fiziksel açıklamaları için de gereksinmez; hem, böyle bir şey (söz gelişi maddesel olmayan şeylerin etkilemesi) ona başka bir yerden sunulsa bile, onu kuşkusuz reddetmesi ve açıklamalarını geliştirirken araya sokmaması; bu açıklamalarını da hep yalnızca, duyu nesnesi olarak deneye giren ve bizim gerçek algımızla deney yasalarına göre bağlantılar içine sokulabilen şeylerle temellendirmesi gerekirdi. Kant, Gelecekte Bilim Olarak Ortaya Çıkabilecek Her Metafiziğe Prolegomena 107. 
deneyimde kalmanın ve yalnızca doğaya bakmanın kısıtlamalarından kurtulmak ister. ${ }^{40}$ Bilindiği üzere ideler deneyimde nesnesi bulunmayan kavrayışlardır. Olanaklı deneyimin mutlak bütünlüğü idelere gönderim yapar. Başka deyişle verilmiş koşullu bir durum açısından zorunlu olan koşullar bütünlüğünün koşulsuzluğudur. Koşullu olan, sınırlara göre düzenlenir ne var ki bu sınırlar aşılmak istenir. İnsan böylesi bir varlıktır. Koşullu olanı aşıp koşulsuza ulaşmak ister. Bir başka deyişle, adanın ötesi deniz, insan için özgürlük alanıdır. Sınırlar insan için neyin bilinebileceğini saptarken, kısıtlamalar bilmenin ötesinde düşünülebilir bir dünya olduğunu imler. Kant açısından noumenonların, sınır-kavramlar olduğunu yukarıda belirtmiştik. Fakat bu sınır-kavramlara ilişkin aklın kısıtlamaları olmasaydı yanılsamalara düşmek kaçınılmaz olurdu. ${ }^{41}$ Öyleyse, sınırlar bilinebilir olanın alanını çizerek olumlu olanla ilişkilendirilirken, kısıtlamalar olumsuzu, aşılamaz olanı imlerler. ${ }^{42}$

Şu durumda anlama yetisiyle ilgili kullanımında kısıtlama bilmenin tüketilmezliği ile, akıl açısından kullanımında ise düşünmenin tüketilemezliği /tamamlanmamışlığı ile ilgilidir.

İmgelem açısından düşünüldüğünde, kısıtlamalar kolaylıkla aşılabilir. İmgelem özgür oyununda kısıtlama tanımayabilir. ${ }^{43}$

\section{Sonuç}

Felsefenin olanağı açısından düşünüldüğünde sınırlandırmalar, herhangi bir olgusal durumun tekilliğini aşan, tümel felsefe yapma tarzının koşuludur. Her felsefe tavrı kendi sınırlarını koymakla ilgili çaba içerir. Neyin var olduğu, bilinebileceği, sınırların ötesinde olduğunun tartışılması bütün bunları kapsayan başka bir alanı gerektirir. İşte burası kısıtlamalarla imlenen alandır. Eş deyişle sınırlar kendi kendini sınırlandırmaz. Bu sınırlandırmayı kısıtlamalar yapar. Ancak kısıtlamalar da mutlak değildir. Filozoftan filozofa, hatta filozofun kendi kişisel gelişiminin aşamalarında yıkılır. Sözgelimi Hegel Kant'ın kısıtlamalarını şu sözleriyle eleştirir:

40 "Tüm olarak doğal saf aklın asıl işini —onu, sırf doğaya bakmayı bir yana bırakıp olanaklı tüm deneyimin ötesine gitmeye ve bu çabayla (ister bilgi, ister aklımsı çıkarımlar olsun) Metafizik denen şeyi gerçekleştirmek zorunda bırakan işini- oluşturan bütün transendental idelere baktığımda, sanırım, farkına varırım ki, bu doğal yatkınlığın yöneldiği amaç, kavrayışımızı deneyimin kısıtlamalarından [schranken], ve sırf doğaya bakmanın kısıtlamalarından [Schranken], önüme hiç olmazsa saf anlama yetisi nesnelerini kapsayan, hiçbir duyusallığın ulaşamayacağı bir alan açılacak kadar kurtarmaktır.” Kant, Gelecekte Bilim Olarak Ortaya Çıkabilecek Her Metafiziğe Prolegomena 117. $(185,4: 362)$

41 "Aklın kullanılışını sırf olanaklı deneyimle kısıtlayan [einschraenken] ilkelerimiz, kendileri de aşkın duruma gelebilir ve — dikkatli bir eleştiri aklın kısıtlamalarını [Schranke] onun deneyimsel kullanılışında da gözetmese ve iddialarına hedefini çizmeseydi- aklımızın kısıtlamalarını [Schranke] şeylerin kendilerinin olanağının kısıtlamaları [Schranke] olarak ilan edilebilirdi." Kant, Gelecekte Bilim Olarak Ortaya Çıkabilecek Her Metafiziğe Prolegomena 164.

42 (...) bütün sınırlarda [Grenzen] pozitif bir şey vardır (söz gelişi yüzey, cisimsel uzamın sınırıdır, ama kendisi de bir uzaydır; nokta bir çizginin sınırıdır [Grenze], ama yine de uzayda bir yerdir); buna karşılık kısıtlamalar [Schranken] yalnızca negatif olur. Kant, Gelecekte Bilim Olarak Ortaya Çıkabilecek Her Metafiziğe Prolegomena 108.

43 Hayalgücü arada sırada havalarda dolaşırsa, yani ölçülü davranıp kendini deneyimin kısıtlamaları [Schranken] içinde tutmazsa, belki bağışlanabilir; çünkü o böyle bir özgür atılımla canlanır, güçlenir; onun bu atılganlığını dizginlemek, gevşemesini gidermekten her zaman daha kolaydır. Ama işi düşünmek olan anlama yetisi, bunun yerine havalarda dolaşırsa , hiçbir zaman bağışlanamaz; çünkü hayalgücünün havalarda dolaşmalarına, gerektiğinde, sınır [Grenze] koymaya yardım edecek olan ancak odur. Kant, Gelecekte Bilim Olarak Ortaya Çıkabilecek Her Metafiziğe Prolegomena 69. 
"Bir yandan anlama yetisinin yalnızca görünüşlerin bilgisini elde ettiğini, öte yandan bu tür bilginin, bilmenin daha öteye gidemediğinden öte mutlak bir şey olduğunu ve bunun insan bilgisi için doğal mutlak bir kısıtlama [Schranke] olduğunu koruyarak, benimsemek tutarsızlıktır.” ${ }^{44}$

Daha sonra ise kısıtlamaların aşılabilir olduğunu Hegel şöyle duyurur: ${ }^{45}$

Felsefenin her bir bölümü felsefi bir bütündür, kendini kendi içinde kapayan bir çemberdir; ama felsefi İdea özel bir belirlilik ya da öğe içinde oradadır. Tekil çember, kendi içinde bütünlük olduğu için, kendi öğesinin kısıtlamalarını [Schranke] parçalayarak daha geniş bir alan [sphaere] kurar; bütün kendini buna göre her biri zorunlu bir aşama [moment] olan çemberlerden bir çember olarak sunar, öyle ki kendine özgü öğelerinin dizgesi bütün İdeayı oluşturur ve İdea da kendi payına eşit ölçüde her bir tekil çemberde görünür.

Felsefi tavrın birliği sınırlar-kısıtlamalar arasındaki bağıntıda kurulur. Bu bağıntı yoluyla filozoflar adaları betimler, denizlere işaret eder. Böylece sınırlar değiştirilir, yeniden düzenlenir, ilkeler ya da yasalar ortaya konulur.

Sınırlar-kısıtlamalar arasındaki bağıntının tüketilemezliği philosopia perennis’tir: Hep yeniden doğan felsefe. Felsefede tartışmaların tüketilemezliği sınırlandırmalarla ilgilidir. Gerçekten de Kant sonrası Alman İdealizmi, Kant'ın kısıtlamalarını ortadan kaldırıp, felsefede yeni sınırları çizmiştir ya da olanları silikleştirmiştir. Örneğin Hegel'in sınırı iki belirlenimi yalnızca birbirinden ayırarak değil aynı zamanda birleştirerek belirlemesi başka bir deyişle sınırları silikleştirerek yaptığı sınırsızlık vurgusu $^{46}$ yeni kısitlamaları imler.

Şu durumda yeni sınırlandırmalar yoluyla felsefi etkinliğin sonu yoktur. Felsefeyi bitirdiğini öne süren Wittgenstein bile, kısıtlamaların farkında olarak merdiveni tekmelemek zorunda kalır. ${ }^{47}$

44 Georg Wilhelm Friedrich Hegel, Encyklopädie der philosophischen Wissenschaften im Grandrisse (Berlin: Verlag von L. Heimann, 1870) \$62 86 .

45 Georg Wilhelm Friedrich Hegel, Encyklopädie der philosophischen Wissenschaften im Grandrisse (Berlin: Verlag von L. Heimann, 1870) \$15 45.

46 Enver Orman, Hegel’in Mutlak İdealizmi (İstanbul: Belge Yayınları, 2015) 146.

47 "Benim tümcelerim şu yolla açımlayıcıdırlar ki, beni anlayan, sonunda bunların anlam-dışı [Unsinning] olduklarını görür, onlarla— onlara tırmanarak—onların üstüne çıktığında. (Sanki üstüne tırmandıktan sonra merdiveni devirip yıkması gerekir.)" Wittgenstein Ludwig, Tractatus Logico-Philosophicus, çev. Oruç Aruoba (İstanbul: Metis, 2013) 6.54173 . 
Çünkü sınır ${ }^{48}$ çizmenin olanağını ortaya koyan sınırlar değil kısıtlamalardır. Bu açıdan Wittgenstein’a göre dünyanın dışında kalan ve onun anlam-dışı [Unsinning] alanı olarak betimlediği kısıtlamalardan söz etmek yerindedir. Nasıl Kant "insan aklı hiçbir sınır tanımaz, ancak kısıtlamalar tanır; yani kendi dışında, hiç ulaşamayacağı bir şeyin olduğunu kabul eder, ama kendisinin, kendi iç gelişiminde tamamlanacağını değil” diyorsa ya da başka türlü söylersek nasıl Kant hem olanaklı deneyimin tamamlanamaz oluşuna hem de deneyimin ötesinin belirlenemeyişine ilişkin kısıtlamalardan söz ediyorsa, Wittgenstein da yanıtlarını bulamadığı bu nedenle hakkındaki felsefi soruları ortadan kaldırmak zorunda kaldığı bir bağlamı imler. ${ }^{49} \mathrm{Ne}$ var ki bu etik estetik bağlam, ondan önce ve sonra başka filozofların özellikle felsefe yapmayı seçtiği alanlardır.

Öyleyse felsefi sorunu çözen de ortadan kaldıran da filozofun sınır-kısıtlama kavrayışıdır. Bir başka deyişle ne türden şeylerin var olduğunu ortaya koyan filozof kısıtlama alanında gezinir, sonra bu var olanların iç belirlenimlerini ortaya koyarken de sınırları saptar.

Finansal Destek: Yazar bu çalışma için finansal destek almamıştır.

48 Wittgenstein, Trastatus'ta sınırı şöyle kullanır:

"Kitap böylece, düşünmeye bir sınır [Grenze] çizmek istiyor, ya da, daha çok— düşünmeye değil, düşüncelerin dile getirilişine: Çünkü düşünmeye bir sınır [Grenze] çizmek için, bu sınırın [Grenze] iki yanını da düşünebilmemiz gerekirdi (yani düşünülmeye elvermeyeni düşünebilmemiz gerekirdi).

Sınır [Grenze], öyleyse, yalnızca dilin içinden çizilebilecektir, ve sınırın ötesinde kalan da, düpedüz anlam-dışı [Unsinn] olacaktır. Özsöz Felsefe, başka türlü sanki bulanık ve kaypak olan düşünceleri, açık kılmalı, keskin olarak sınırlamalıdır [Abgrenzen]. 4.112 Empirik gerçeklik, nesnelerin toplamı yoluyla sınırlanır (Begrenzt). Sınır [Grenze], temel tümcelerin toplamında kendini yeniden gösterir. 5.5561 Dilimin sınırları[grenzen], dünyamın sınırlarına [Grenzen] gönderim (Bedeuten) yapar. 5.6 Mantık dünyayı doldurur; dünyanın sınırları [Grenzen] onun da sınırlarıdır [Grenzen]. 5.61 Dünyanın b e n i m dünyam olduğu, kendini şurada gösterir ki, dilin (yalnızca benim anladığım dilin) sınırları [Grenzen] benim dünyamın sınırlarına [Grenzen] gönderim yapar. 5.62"

49 Şöyle demektedir: "Öyle bir duygumuz vardır ki, bütün olanaklı bilimsel sorular yanıtlandığında bile, yaşam sorunlarımıza daha hiç dokunulmamıştır. Tabiî o zaman da hiçbir soru kalmamıştır; yanıt da tam budur". 6.52

"Yaşam sorununun çözümü, bu sorunun yok olmasında görülür." 6.521 


\section{Kaynaklar}

Aristotle. "Metaphysics". Içinde The Complete Works of Aristotle: the Revised Oxford Translation, editör Jonathan Barnes, C. II. Princeton: Princeton University Press, 2014.

Cohen, Hermann. Kants Theorie der Erfahrung. Berlin: Ferd. Dümmler's, 1871.

Eisler, Rudolf. Kant Lexicon. Hildescheim: Olms, 1961.

Feloj, Serena. “Metaphor and Boundary: H. S. Reimarus' Vernunftlehre As Kant's Source”. Lebenswelt 1, say1 1 (2011): 31-46.

Fulda, F. “Grenze, Schranke”. Içinde Historisches Wörterbuch der Philosophie, editör Joachim Ritter ve Karlfried Gründer. Basel: Schwabe, 1974.

Hegel, Georg Wilhelm Friedrich. Encyklopädie der philosophischen Wissenschaften im Grandrisse. Berlin: Verlag von L. Heimann, 1870.

Kant, Immanuel. Gelecekte Bilim Olarak Ortaya Çıkabilecek Her Metafiziğe Prolegomena. Çeviren İonna Kuçuradi ve Yusuf Örnek. Ankara: Türkiye Felsefe Kurumu, 2002.

. "Kritik der reinen Vernunft". Içinde Kant's gesammelte Schriften Preußische Akademie der Wissenschaften, C. 3. Berlin: Georg Reimer, 1911.

- Kritik Der Reinen Vernunft. Hamburg: Felix Meiner, 1956.

- Lectures on Metaphysics. Çeviren Karl Ameriks ve Steve Naragon. Cambridge: Cambridge University Press, 1997.

Ludwig, Wittgenstein. Tractatus Logico-Philosophicus. Çeviren Oruç Aruoba. İstanbul: Metis, 2013.

Orman, Enver. Hegel’in Mutlak İdealizmi. İstanbul: Belge Yayınları, 2015.

Pehlivan, Ebru. “Kant’ın Eleştiri Öncesi Eserlerinde Sınır Kavramı”. Felsefe Arkivi II, sayı 47 (2017): $43-67$.

_. "Kant'ta Öznenin Bilme, Eyleme ve İnanma Bakımından Sınırları”. Içinde Uluslararası İstanbul Felsefe Kongresi Bildiri Kitabı, editör Mehmet Günenç, 99-111. İstanbul: Mantık Derneği Yayınları, 2018.

Plato. "Phaedrus". Içinde Complete works, editör D S Hutchinson John M.Cooper, xxx, 1808 p. Indianapolis, Ind.: Hackett Pub., 1997.

Grimm, Jacob. Deutsches Wörterbuch. München: Dt. Taschenbuch, 1999.

Keskin, Gamze. "Kant'ın Ontolojik Kanıt Eleştirisinin Epistemolojik Temelleri". FLSF (Felsefe ve Sosyal Bilimler Dergisi), Sayı 27 (2019): 97-116. 